\title{
Faktor yang Berhubungan dengan Stimulasi Toilet Training pada Anak Usia Toddler (1-3 Tahun) di Wilayah Kerja Puskesmas Rasimah Ahmad Kota Bukittinggi
}

\author{
Kriscillia Molly Morita ${ }^{1, a^{*}}$, Liza Merianti ${ }^{2, b}$, Oma Marisa ${ }^{3, c}$ \\ ${ }^{1}$ Program Studi D3 Keperawatan STIKes yarsi sumatera barat bukittinggi, 26136 Indonesia \\ ${ }^{2}$ Program Studi D3 Keperawatan STIKes Yarsi Sumatera Barat bukittinggi, 26136 Indonesia \\ ${ }^{3}$ Program Studi Ners STIKes Yarsi sumatera Barat Bukittinggi, 26136, Indonesia \\ akriscillia1981@ gmail.com*; ${ }^{b}$ lizamerianti@stikesyarsi.ac.id ; ${ }^{c}$ Omamarisa65@gmail.com \\ * corresponding author
}

ARTICLE INFO

Keywords:

Stimulation Factors

Knowledge

Education

Family Support

\section{ABSTRACT}

Toilet training trains children to control their bowel and bladder. However, many mothers do not carry out toilet training stimulation for toddlers because they do not know the benefits are very great in growing children's independence. Toilet training teaches children to clean their own feces and reuse their pants. The purpose of this study is to find out the factors associated with toilet training stimulation in toddler age children in the Rasimah Ahmad Community Health Center in Bukittinggi in 2019, the factors studied were mother's knowledge, education mother and family support with toilet training stimulation in toddler age children. The research design was descriptive analytic using a cross sectional approach with a sample of 139 mothers, data processing was performed using the Chi-Square test. This study proves that there is a significant relationship between knowledge, education and family support with toilet training stimulation in toddler age children with a PV of 0.001 . It is expected that Pukesmas officers and holders of maternal and child health programs will incorporate toilet training into the health education program at the posyandu.

\section{Pendahuluan}

Golden age atau masa keemasan, adalah masa-masa penting anak yang tidak bisa diulang. Pada masa-masa ini, kemampuan otak anak untuk menyerap informasi sangat tinggi. Apapun informasi yang diberikan akan berdampak bagi anak di kemudian hari. Di masa-masa inilah, peran orang tua dituntut untuk bisa mendidik dan mengoptimalkankecerdasan anak baik secara intelektual, emosional dan spiritual. Usia tersebut merupakan waktu yang tepat bagi anak untuk mempelajari berbagai macamketerampilan seperti belajar buang air besar dan buang air kecil, membentuk kebiasaankebiasaan yang akan berpengaruh pada masa-masa kehidupan selanjutnya [1]

Salah satu tugas perkembangan anak usia 3 tahun adalah Toilet training.Toilet training merupakan salah satu tugas dari perkembangan anak pada usia toddler [2]. Toilet Training merupakan cara untuk melatih anak agar bisa mengontrol buang air besar (BAB) dan buang air kecil (BAK). Hal ini penting dilakukan untuk melatih kemandirian anak dalam malakukan BAB dan BAK sendiri. Toilet training baik dilakukan sejak dini untuk menanamkan kebiasaan yang baik pada anak. Toilet training akan dapat berhasil dengan baik apabila ada kerjasama antara orang tua dan anak. Kerjasama yang baik akan memberikan saling percaya pada orang tua dan anak. 
Berdasarkan Penelitian yang telah dilakukan dalam jurnal penelitian Pemberian pendidikan stimulasi ibu memengaruhi kesiapan toilet training anak toddler. Diharapkan ibu untuk dapat memahami informasi yang diberikan dan dapat memberikan stimulasi tentang toilet training kepada anak sesering mungkin [3]. Menurut teori Soekanto, faktor pendidikan ibu berperan penting dalam memengaruhi tingkat pengetahuan ibu. Umumnya seseorang yang berpendidikan tinggi akan memiliki pengetahuan lebih luas dibandingkan seseorang dengan tingkat pendidikan yang rendah. Semakin tinggi pendidikan seseorang maka akan semakin mudah seseorang tersebut dalam menerima hal-hal baru.

Menstimulasi perkembangan anak merupakan salah satu upaya dalam rangka pemenuhan kebutuhan asuh, asah, asih untuk mencapai perkembangan anak secara optimal. Stimulasi merupakan hal yang sangat penting, karena anak yang mendapatkan stimulasi akan cepat berkembang dibandingkan dengan anak yang kurang bahkan tidak mendapatkan stimulasi. Namun dalam kenyataannya masih banyak orang tua belum memahami bagaimana cara mengasuh anak secara efektif dan memberikan stimulasi kepada anak untuk mencapai perkembangan yang optimal. Dari penjelasan tersebut menunjukkan bahwa stimulasi sangatlah penting untuk mencapai perkembangan yang optimal. Pemberian pendidikan stimulus merupakan strategi yang baik untuk menyiapkan dan meningkatkan kemampuan orang tua (terutama ibu) dalam berperan aktif menstimulasi perkembangan anaknya [4].

Di Indonesia, anak laki-laki lebih banyak menunjukkan gejala anuresia (mengompol) dibanding dengan anak perempuan dengan perbandingan 3:1. Berdasarkan survei, sekitar 30\% anak berusia 4 tahun, $10 \%$ anak berusia 6 tahun dan 3\% anak berusia 15 tahun mengompol pada malam hari [5]. Menurut Syahid (2009), tingkat pengetahuan ibu tentang toilet training pada anak usia toddler sebagian besar tidak baik sebanyak $63,8 \%$. Penerapan toilet training pada anak usia toddler (1-3 tahun) sebagian besar tidak diterapkan sebanyak $56,4 \%$.

Dampak yang paling umum terjadi dalam kegagalan toilet training diantaranya adalah adanya perlakuan atau aturan yang ketat dari orangtua kepada anaknya dapat mengganggu kepribadian anak dan cenderung bersikap keras kepala bahkan kikir, seperti orangtua sering memarahi anak pada saat BAB atau BAK atau bahkan melarang BAB atau BAK saat bepergian. Selain itu, apabila orangtua juga santai dalam memberikan aturan dalam toilet training, maka anak dapat mengalami kepribadian ekspresif, seperti anak menjadi lebih tega, cenderung ceroboh, suka membuat gara-gara, emosional, dan seenaknya dalam melakukan kegiatan sehari-hari [1]. Selain itu, apabila dilakukan toilet training pada anak dengan usia yang tidak tepat dapat menimbulkan beberapa masalah yang dialami anak yaitu seperti sembelit, menolak toileting, disfungsi berkemih, infeksi saluran kemih, dan enuresis [6].

Hasil studi retrospektif kasus kontrol yang dilakukan oleh Kiddoo [7] menunjukkan bahwa anakanak yang selalu diberi hukuman oleh ibunya pada saat melakukan kesalahan dalam toilet training anak dapat mengalami gejala inkontinensia atau ISK. Sedangkan pada anak yang mendapatkan motivasi dari ibunya pada saat melakukan toilet training anak dapat mengalami gejala inkontinensia dan ISK yang lebih rendah. Bentuk hukuman pada saat toilet training juga menimbulkan bahaya karena anak akan belajar perilaku agresif dalam mengatasi rasa marah [8]. Sementara itu, anak-anak yang selalu diberikan reinforcement positif oleh ibunya maka anak akan semakin termotivasi untuk melakukan toilet training.

Kesiapan pada anak untuk melakukan toileting training, pengetahuan orangtua mengenai toilet training, dan pelaksanaan toileting yang baik dan benar pada anak, merupakan suatu domain penting yang perlu orangtua ketahui. Domain tersebut dapat Septian A: Analisis Faktor-Faktor yang berhubungan dengan Kebersihan Toilet Training 148 Volume 2 Nomor 3 Desember 2014 meningkatkan kemampuan toileting training pada anak usia toddler [9]. Perubahan perilaku anak bergantung kepada kualitas rangsangan yang berkomunikasi dengan lingkungan. Keberhasilan perubahan perilaku yang terjadi pada anak sangat ditentukan oleh kualitas dari sumber stimulus. Untuk membentuk jenis respon atau perilaku perlu diciptakan suatu kondisi yang disebut dengan operant conditioning, yaitu dengan menggunakan urutan-urutan komponen penguat. Komponen-komponen penguat tersebut adalah seperti pemberian hadiah atau penghargaan apabila melakukan suatu hal dengan benar [10].

Dari hasil wawancara dan observasi yang telah peneliti lakukan pada tanggal 11 September 2019 pada Posyandu Kenanga Puskesmas Rasimah Ahmad Bukittinggi peneliti mendapatkan data jumlah balita 72 orang, usia 1-3 tahun berjumlah 50 orang. Dari pengamatan yang penulis lakukan ditemukan pada 20 orang ibu yang mempunyai anak usia 1-3 tahun (toddler) yang berkunjung ke Posyandu Kenanga Puskesmas Rasimah Ahmad Bukittinggi, 16 dari 20 orang ibu mengatakan tidak mengetahui tentang latihan ke toilet (toilet training). Yang menyebabkan ibu mengeluh bahwasanya anaknya sering buang air disembarangan tempat tanpa pemberitahuan kepada si ibu sebelumnya dan mengatakan rumahnya menjadi kotor dan bau.

Dari fenomena inilah penulis dapat melihat bahwa ibu tersebut tidak mengetahui tentang latihan ke toilet (toilet training) itu dengan sepenuhnya. Dimana ibu-ibu tersebut kurang 
mendapatkan informasi/penyuluhan dan tidak terlalu paham tentang perawatan anak pada usia 1-3 tahun (toddler) dan tidak mengetahui apa sebenarnya tujuan akhir dari toilet training pada anak.

Berdasarkan latar belakang masalah tersebut di atas dan mengingat pentingnya toilet training bagi anak, maka menarik untuk diteliti tentang faktor-faktor yang berhubungan dengan stimulasi toilet training pada anak usia toddler (1-3 tahun) di Wilayah Kerja Puskesmas Rasimah Ahmad Bukittinggi.

\section{Metode}

Jenis penelitian ini adalah penelitian analitik dengan desain cross sectional [11]. Tujuan penelitian ini adalah untuk mengetahui faktor-faktor yang berhubungan dengan stimulasi toilet training pada anak usia toodler di wilayah kerja Puskesmas Rasimah Ahmad tahun 2019. Jumlah sampel penelitian ini adalah 139 orang ibu balita yang memiliki anak usia toddler yang diperoleh dengan teknik simple random sampling. Data primer diperoleh dengan melakukan wawancara menggunakan kuesioner dan data sekunder diperoleh dari perusahaan yang meliputi data ibu balita dari 23 posyandu dari tahun 2019.

\section{Hasil dan Pembahasan}

1. Analisis Univariat

a. Pengetahuan Ibu

Tabel 1. Distribusi Frekuensi Pengetahuan Ibu yang Memiliki Anak Usia Toodler Di Wilayah Kerja Puskesmas Rasimah Ahmad Kota Bukittinggi tahun 2019

\begin{tabular}{cccc}
\hline No & Pengetahuan & Jumlah & Persentase \\
\hline 1 & Rendah & 47 & 33,8 \\
2 & Tinggi & 92 & 66,2 \\
& Total & 139 & 100 \\
\hline
\end{tabular}

Tabel 1. dapat diketahui bahwa sebagian besar ibu yang memiliki anak usia toddler di wilayah kerja Puskesmas Rasimah Ahmad memiliki pengetahuan yang tinggi tentang toilet training yaitu sebanyak 92 orang $(66,2 \%)$.

b. Pendidikan Ibu

Tabel 2. Distribusi Frekuensi Pendidikan Ibu yang Memiliki Anak Usia Toodler Di Wilayah Kerja Puskesmas Rasimah Ahmad Kota Bukittinggi tahun 2019

\begin{tabular}{cccc}
\hline No & Pendidikan & Jumlah & Persentase \\
\hline 1 & Rendah & 41 & 29,5 \\
2 & Tinggi & 98 & 70,5 \\
& Total & 139 & 100 \\
\hline
\end{tabular}

Tabel 2. dapat diketahui bahwa sebagian besar ibu yang memiliki anak usia toddler di wilayah kerja Puskesmas Rasimah Ahmad memiliki pendidikan yang tinggi tentang toilet training yaitu sebanyak 98 orang $(70,5 \%)$.

c. Dukungan Keluarga

Tabel 3. Distribusi Frekuensi Dukungan Keluarga yang Memiliki Anak Usia Toodler Di Wilayah Kerja Puskesmas Rasimah Ahmad Kota Bukittinggi tahun 2019

\begin{tabular}{cccc}
\hline No & Dukungan Keluarga & Jumlah & Persentase \\
\hline 1 & Rendah & 48 & 34,5 \\
2 & Tinggi & 91 & 65,5 \\
& Total & 139 & 100 \\
\hline
\end{tabular}

Tabel 3 dapat diketahui bahwa sebagian besar ibu yang memiliki anak usia toddler di wilayah kerja Puskesmas Rasimah Ahmad memiliki dukungan keluarga tergolong tinggi tentang toilet training yaitu sebanyak 91 orang $(65,5 \%)$. 


\section{d. Stimulasi Toilet Training}

Tabel 4. Distribusi Frekuensi Stimulasi Toilet Trainingyang Dilakukan Ibu Pada Anak Usia Toodler Di Wilayah Kerja Puskesmas Rasimah Ahmad Kota Bukittinggi tahun 2019

\begin{tabular}{cccc}
\hline No & Stimulasi Toilet Training & Jumlah & Persentase \\
\hline 1 & Tidak Dilakukan & 65 & 46,8 \\
2 & Dilakukan & 74 & 53,2 \\
& Total & 139 & 100 \\
\hline
\end{tabular}

Tabel 4 dapat diketahui bahwa pelaksanaan toilet training pada anak usia toddler di wilayah kerja Puskesmas Rasimah Ahmad sebagian besar sudah dilakukan ibu yaitu sebanyak 74 orang $(53,2 \%)$.

\section{Hasil Analisa Bivariat}

1. Hubungan Pengetahuan dengan Toilet Training

Tabel 5. Hubungan Pengetahuan dengan Pelaksanaan Toilet Training Pada Ibu yang Memiliki Anak Usia Toodler Di Wilayah Kerja Puskesmas Rasimah Ahmad Kota Bukittinggi tahun 2019

\begin{tabular}{|c|c|c|c|c|c|c|}
\hline \multirow{2}{*}{ Pengetahuan } & \multicolumn{4}{|c|}{$\begin{array}{r}\text { Toilet Training } \\
\end{array}$} & \multirow{2}{*}{\multicolumn{2}{|c|}{ Total }} \\
\hline & \multicolumn{2}{|c|}{ Tidak dilakukan } & \multicolumn{2}{|c|}{ Dilakukan } & & \\
\hline & $\begin{array}{l}\text { Frekuensi } \\
\text { (n) }\end{array}$ & $\begin{array}{l}\text { Persentasi } \\
(\%)\end{array}$ & $\begin{array}{l}\text { Frekuensi } \\
\text { (n) }\end{array}$ & $\begin{array}{l}\text { Persentasi } \\
(\%)\end{array}$ & $\begin{array}{l}\text { Frekuensi } \\
\text { (n) }\end{array}$ & $\begin{array}{l}\text { Persentasi } \\
(\%)\end{array}$ \\
\hline Rendah & 44 & 93,6 & 3 & 6,4 & 47 & 100 \\
\hline Tinggi & 21 & 22,8 & 71 & 77,2 & 92 & 100 \\
\hline Total & 65 & 46,8 & 74 & 53,2 & 139 & 100 \\
\hline
\end{tabular}

Tabel 5 dapat diketahui bahwa proporsi ibu yangmelaksanakan stimulasi toilet trainingpada ibu yang berpengetahuan rendah yaitu sebanyak 3 orang ( 6,4 \%) sedangkan ibu yang berpengetahuan rendah yang tidak melaksanakan stimulasi toilet trainingsebanyak 44 orang $(93,6 \%)$

\section{Hubungan Pendidikan dengan Toilet Training}

Tabel 6. Hubungan Pendidikan dengan Pelaksanaan Toilet Training Pada Ibu Yang Memiliki Anak Usia Toodler Di Wilayah Kerja Puskesmas Rasimah Ahmad Kota Bukittinggi tahun 2019

\begin{tabular}{|c|c|c|c|c|c|c|}
\hline \multirow{3}{*}{ Pendidikan } & \multicolumn{4}{|c|}{ Toilet Training } & \multicolumn{2}{|c|}{ Total } \\
\hline & \multicolumn{2}{|c|}{ Tidak dilakukan } & \multicolumn{2}{|c|}{ Dilakukan } & & \\
\hline & $\begin{array}{l}\text { Frekuensi } \\
\text { (n) }\end{array}$ & $\begin{array}{c}\text { Persentasi } \\
(\%)\end{array}$ & $\begin{array}{l}\text { Frekuensi } \\
\text { (n) }\end{array}$ & $\begin{array}{c}\text { Persentasi } \\
(\%)\end{array}$ & Frekuensi (n) & $\begin{array}{c}\text { Persentasi } \\
(\%)\end{array}$ \\
\hline Rendah & 41 & 100 & 0 & 0 & 41 & 100 \\
\hline Tinggi & 24 & 24,5 & 74 & 75,5 & 98 & 100 \\
\hline Total & 65 & 46,8 & 74 & 53,2 & 139 & 100 \\
\hline
\end{tabular}

Tabel 6 dapat diketahui bahwa proporsi ibu yang melaksanakan stimulasi toilet training pada ibu yang berpendidikan rendah yaitu sebanyak 0 orang $(0 \%)$ sedangkan ibu yang tidak melaksanakan stimulasi toilet trainingberpendidikan rendah sebanyak 41 orang $(100 \%)$.

Distribusi data di atas memperlihatkan adanya kecendrungan bahwa semakin rendah pengetahuan maka semakin rendah pula proporsi pelaksanaan toilet training pada anak usia toddler. Hasil analisa statistik dengan uji chi-square diperoleh nilai $p$ sebesar $0,001(p<0,05)$ artinya terdapat perbedaan proporsi pelaksanaan toilet training pada ibu yang berpengetahuan rendah dan 
tinggi. Dengan kata lain secara statistik disebutkan bahwa terdapat hubungan yang signifikan antara pengetahuan ibu dengan pelaksanaan toilet training pada anak usia toddler.

Distribusi data di atas diatas memperlihatkan adanya kecendrungan bahwa semakin rendah pendidikan maka semakin rendah pula proporsi pelaksanaan toilet training pada anak usia toddler. Hasil analisa statistik dengan uji chi-square diperoleh nilai $\mathrm{p}$ sebesar $0,001 \quad(\mathrm{p}<0,05)$ artinya terdapat perbedaan proporsi pelaksanaan toilet training pada ibu yang berpendidikan rendah dan tinggi. Dengan kata lain secara statistik disebutkan bahwa terdapat hubungan yang signifikan antara pendidikan ibu dengan pelaksanaan toilet training pada anak usia toddler.

\section{Hubungan Dukungan Keluarga dengan Toilet Training}

Tabel 7. Hubungan Dukungan Keluarga dengan Pelaksanaan Toilet Training Pada Ibu Yang Memiliki Anak Usia Toodler Di Wilayah Kerja Puskesmas Rasimah Ahmad Kota Bukittinggi tahun 2019

\begin{tabular}{|c|c|c|c|c|c|c|}
\hline \multirow{3}{*}{$\begin{array}{l}\text { Dukungan } \\
\text { Keluarga }\end{array}$} & \multicolumn{4}{|c|}{ Stimulasi Toilet Training } & \multirow{2}{*}{\multicolumn{2}{|c|}{ Jumlah }} \\
\hline & \multicolumn{2}{|c|}{ Tidak dilakukan } & \multicolumn{2}{|l|}{ Dilakukan } & & \\
\hline & $\begin{array}{l}\text { Frekuensi } \\
\text { (n) }\end{array}$ & $\begin{array}{l}\text { Persentasi } \\
(\%)\end{array}$ & $\begin{array}{l}\text { Frekuensi } \\
\text { (n) }\end{array}$ & $\begin{array}{l}\text { Persentasi } \\
(\%)\end{array}$ & Frekuensi (n) & $\begin{array}{l}\text { Persentasi } \\
(\%)\end{array}$ \\
\hline Negatif & 42 & 87,5 & 6 & 12,5 & 48 & 100 \\
\hline Positif & 23 & 25,3 & 68 & 74,7 & 91 & 100 \\
\hline Total & 65 & 46,8 & 74 & 53,2 & 139 & 100 \\
\hline
\end{tabular}

$X=48,875$

$\mathrm{Pv}=0,001$

Tabel 7 dapat diketahui bahwa proporsi ibu yang melaksanakan stimulasi toilet trainingpada ibu yang dukungan keluarga negatif yaitu sebanyak 6 orang (12,5\% ) sedangkan ibu yang dukungan keluarga negative yang tidak melakukan stimulasi toilet trainingsebanyak 42 orang $(87,5 \%)$. Distribusi data diatas diatas memperlihatkan adanya kecendrungan bahwa semakin negatif dukungan keluarga maka semakin rendah pula proporsi pelaksanaan toilet training pada anak usia toddler. Hasil analisa statistik dengan uji chi-square diperoleh nilai p sebesar 0,001 ( $p<$ $0,05)$ artinya terdapat perbedaan proporsi pelaksanaan toilet training pada ibu yang dukungan keluarga negatif dan positif.

Berdasarkan penelitian responden yang memiliki pengetahuan yang tergolong tinggi tentang stimulasi toilet training sebanyak 92 orang $(66,2 \%)$. Dari hasil wawancara ada 92 responden, 71 orang diantaranya berpengetahuan tinggi ini didapat dari soal nomor 6 yang menyatakan bahwa tindakan ibu jika anak takut ke toilet adalah sabar dan terus mencoba, dan juga soal nomor 7 yang menyatakan bahwa disini ibu selalu memperhatikan cara toilet, menjaga kebersihan dan tidak memaksa anak. Didapat juga ibu berpengetahuan rendah sebanyak 47 orang, ada 44 orang yang tidak melalukan toilet training pada anak ini didapat dari soal nomor 25 yang menyatakan bahwa ibu berasumsi dengan memakai pampers memudahkan anak ke toilet.

Dari 139 responden yang telah dilakukan peneliti ternyata ibu yang memiliki anak usia toddler di wilayah kerja Puskesmas Rasimah Ahmad yang berpendidikan tinggi sebanyak 98 orang (70,5\%). Pada penelitian ini masih ada pendidikan ibu SD-SMP sebanyak 41 orang, disini ibu tidak ada melakukan toilet training kepada anak usia toddler dengan alasan bekerja di luar rumah membantu suami mencari nafkah, sehingga tidak punya waktu lagi memikirkan kesuksesan tumbunuh kembang anak pada masa keemasan perkembangannya. Sedangkan ibu yang berpendidikan tinggi sebanyak 98 orang, ada 74 orang yang melakukan toilet training karena ibu sangat memikirkan kesuksesan masa keemasan perkembangan anak usia toddler. 
Dari hasil penelitian didapatkan bahwa sebagian besar dukungan keluarga terhadap toilet training pada anak usia toddler tergolong positif sebanyak 91 orang $(65,5 \%)$. Hasil penelitian ini yang menyatakan 91 dukungan keluarga positif 68 diantaranya didapat dari bahwa dalam pelaksanaan toilet training pada anak ibu selalu dibantu oleh keluarga, dan yang menyatakan 48 orang dukungan keluarga negatif 42 diantaranya tidak melakukan toilet training pada anak usia toddler, didapat bahwa keluarga ibu belum cepat membawa anak ke toilet jika anak menunjukkan tanda mau BAB dan BAK.

\section{Pembahasan}

1. Faktor -faktor yang berhubungan dengan Stimulasi Toilet Training

a. Hubungan Pengetahuan dengan Stimulasi Toilet Training

Menurut peneliti tingkat pengetahuan ibu mengenai toilet training yang dinilai dalam penelitian ini masih berada pada tingkat tahu,secara garis besar terbatas dari hasil pengindraan dan pengalaman ibu dalam membimbing anak untuk berhajad pada tempat yang sebenarnya dan sebatas menjaga kebersihan rumah agar tidak bau. Berdasarkan hasil uji chi-square diperoleh nilai $p$ value $=0,001<0,05$ yang berarti bahwa ada hubungan yang bermakna antara pengetahuan dengan stimulasi toilet training pada anak usia toddler di wilayah kerja Puskesmas Rasimah Ahmad tahun 2019.

Penelitian ini sama dengan penelitian elsera [12]. Tingkat pengetahuan berhubungan dengan sikap ibu dalam toilet training pada Toddler dengan hasil penelitian bahwa tingkat pengetahuan responden baik. Sikap responden sebagian besar mendukung toilet training. Ada hubungan antara tingkat pengetahuan dengan sikap ibu dalam toilet training pada anak usia toddler. Sesuai dengan teori Notoadmodjo [11] pengetahuan merupakan hasil dari tahu dan ini terjadi setelah orang melakukan penginderaan terhadap objek tertentu. Penginderaan terjadi melalui indera manusia, yakni indra penglihatan, pendengaran, penciuman, rasa dan raba. Sebagian besar pengetahuan manusia diperoleh melalui mata dan telinga.

\section{b. Hubungan Pendidikan dengan Stimulasi Toilet Training}

Berdasarkan uji chi square yang dilakukan, diperoleh nilai $p$-value $=0,001<0,05$ yang berarti bahwa ada hubungan yang bermakna antara pendidikan dengan stimulasi toilet training pada anak usia toddler di wilayah kerja Puskesmas Rasimah Ahmad tahun 2019. Menurut Binawarti (2006) hasil penelitian menunjukkan terdapat pengaruh antara pendidikan dengan stimulasi toilet training pada anak toddler dengan $p$-value $<0,05$. Pada penelitian ini masih ada pendidikan ibu SD-SMP sebanyak 41 orang, disini ibu tidak ada melakukan toilet training kepada anak usia toddler dengan alasan bekerja di luar rumah membantu suami mencari nafkah, sehingga tidak punya waktu lagi memikirkan kesuksesan tumbunh kembang anak pada masa keemasan perkembangannya. Sedangkan ibu yang berpendidikan tinggi sebanyak 98 orang, ada 74 orang yang melakukan toilet training karena ibu sangat memikirkan kesuksesan masa keemasan perkembangan anak usia toddler.

Menurut I Green (1980) dalam buku Notoadmojo [11], jika sesorang memiliki pendidikan tinggi maka sikap dan perilakunya akan baik. Pendidikan merupakan salah satu aspek sosial yang umumnya berpengaruh pada tingkah laku manusia. Pendidikan berarti bimbingan yang diberikan seseorang kepada perkembangan orang lain menuju ke arah yang lebih baik,karena makin tinggi pendidikan sesorang maka semakin mudah sesorang itu menerima informasi, sehingga makin banyak pula pengetahuan yang dimilikinya dan sebaliknya pendidikan yang rendah akan menghambat perkembangan terhadap nilai-nilai dan perubahan yang baru dikenalnya dan yang memengaruhi terhadap penerimaan suatu informasi khususnya tentang kesehatan [11].

Menurut peneliti tingkat pendidikan ibu yang memiliki anak usia toddler sangat memengaruhi ibu dalam mengajarkan anak untuk latihan ke toilet yang benar, karena proses pencapaian dan penerimaan informasi ini akan cepat jika responden memiliki pendidikan yang tinggi. 
c. Hubungan Dukungan Keluarga dengan Stimulasi Toilet Training

Berdasarkan uji chi square yang dilakukan, diperoleh nilai $p$-value $=0,001<0,05$ yang berarti bahwa ada hubungan yang bermakna antara dukungan keluarga dengan stimulasi toilet training pada anak usia toddler di wilayah kerja Puskesmas Rasimah Ahmad tahun 2019.

Dari hasil penelitian didapatkan bahwa sebagian besar dukungan keluarga terhadap toilet training pada anak usia toddler tergolong positif sebanyak 91 orang $(65,5 \%)$. Hasil penelitian ini yang menyatakan 91 dukungan keluarga positif 68 diantaranya didapat dari bahwa dalam pelaksanaan toilet training pada anak ibu selalu dibantu oleh keluarga, dan yang menyatakan 48 orang dukungan keluarga negatif 42 diantaranya tidak melakukan toilet training pada anak usia toddler, didapat bahwa keluarga ibu belum cepat membawa anak ke toilet jika anak menunjukkan tanda mau BAB dan BAK.

Menurut Zakiyah (2019) menyatakan bahwa sebagian besar responden $70 \%$ menunjukkan dukungan keluarga positif, dan $30 \%$ dukungan keluarga negatif. Dukungan keluarga memengaruhi toilet training anak karena lingkungan keluarga merupakan lingkungan pendidikan yang pertama dan utama bagi anak, karena dalam keluarga inilah seorang anak manusia pertama sekali mendapatkan pendidikan dan bimbingan. Pengalaman yang diperoleh anak melalui pendidikan dalam keluarga akan memengaruhi perkembangan anak dalam proses pendidikan selanjutnya. Dukungan keluarga dapat membantu meningkatkan keberhasilan toilet training anak. Apabila anak menerapkan toilet training dengan baik dan berhasil maka anak juga akan menerima manfaat dari toilet training tersebut, misalnya dapat membuka celana dan memakai celana sendiri, dapat membedakan kotor dan bersih karena anak sebelumnya mengompol yang membuat tidak nyaman dengan rasa dan baunya, dapat menjaga kebersihan karena dapat cebok dan menyiram toilet secara mandiri, dapat membedakan tempat/ruangan karena setiap tempat berbeda jenis dan fungsinya, dan sebagainya. Hal ini juga memperkuat mempertajam perkembangan kognitif, motorik halus, motorik kasar [10].

\section{Kesimpulan}

Berdasarkan hasil penelitian dan pembahasan yang telah diuraikan pada bab sebelumnya, maka dapat diambil kesimpulan sebagai berikut.

1. Sebagian besar responden memiliki pengetahuan tinggi, pendidikan tinggi dan dukungan keluarga positif tentang toilet training.

2. Sebagian besar responden sudah melaksanakan toilet training pada anak usia toddler

3. Terdapat hubungan yang signifikan antara pengetahuan ibu dengan pelaksanaan toilet training pada anak usia toddler sehingga Ha diterima, dan Ho ditolak.

4. Terdapat hubungan yang signifikan antara pendidikan ibu dengan pelaksanaan toilet training pada anak usia toddler, sehingga Ha diterima, dan Ho ditolak.

5. Terdapat hubungan yang signifikan antara dukungan keluarga dengan pelaksanaan toilet training pada anak usia toddler, sehingga Ha diterima, dan Ho ditolak.

\section{Referensi}

[ 1 ] Hidayat, A.A.A. (2008). Pengantar Ilmu Keperawatan Anak I. Salemba Medika: Jakarta

[2 ] Hockenbery, M. J., Wilson, D., \& Wong, D. L. (2012). Wong's essential of pediatric nursing 9: Wong's essential of pediatric Septian A: Analisis Faktor-Faktor yang berhubungan dengan Kebersihan Toilet Training Volume 2 Nomor 3 Desember 2014153 nursing. Elsevier Health Sciences.

[ 3 ] Rahmawat.D. N, Sudyasih. Pengaruh Pemberian Stimulasi Ibu Terhadap Kesiapan Toilet Training Anak Toddler Di Desa Sukoreno Sentolo Kulon Progo Yogyakarta

[ 4 ] Anonim.(2012). Pengaruh Penyuluhan Kesehatan Terhadap Kemampuan Menstimulasi Anak Usia 0-12 Bulan, http://www.skripsipedia.com/2012 diakses tanggal 15 November 2014

[5] Paryanti, P. (2013). Hubungan Peran Ibu Dalam Pelaksanaan Toilet Training Dengan Kemampuan Toilet Training Pada Anak Usia 18-36 Bulan Di PosyanduKalirase Trimulyo 
Sleman D.I.Kalirase Trimulyo Sleman D.I.ogyakarta, Skripsi tidak dipublikasikan Stikes „Aisyiyah Yogyakart

[6 ] Hooman, N., Safaii, A., Valavi, E., \& AminiAlavijeh, Z. (2013). Toilet training in Iranian children: a cross-sectional study. Iranian Journal of Pediatrics, 23(2), 154.

[ 7 ] Kiddoo, D. A. (2012). Toilet training children: When to start and how to train. Canadian Medical Association Journal, 184(5), 511- 511.

[ 8 ] Rudolf, M. A. (2006). Buku ajar pediatri, Volume 1. Jakarta: EGC.

[9] Kusumaningrum, A., Natosba, J., \& Julia, E. L. (2011). Pengaruh pendidikan kesehatan terhadap perilaku orangtua dalam toilet training toddler. Jurnal Ilmu Kesehatan Masyarakat, 2(02), 97-102.

[ 10 ] Maulana, H. (2009). Promosi kesehatan. Jakarta: EGC.

[ 11 ] Noto Atmodjo, S. (2003). Metodologi Penelitian Kesehatan. Jakarta : Rineka Cipta.

[12 ] Elsera Chori Tingkat Pengetahuan Berhubungan dengan Sikap Ibu dalam Toilet Training pada Toddler (2016). Journal Ners and Midwifery Indonesia. 